\title{
Subsequent Separation and Selective Extraction of Thorium (IV), Iron (III), Zirconium (IV) and Cerium (III) from Aqueous Sulfate Medium
}

\author{
E.H. Borai ${ }^{a}$, A.M. Shahr El-Din ${ }^{a, k}$, E.M. El Afifi ${ }^{a}$, R.F. Aglan ${ }^{a}$ and M.M. Abo-Aly \\ ${ }^{a}$ Hot Lab. Center, Atomic Energy Authority, Cairo 13759, Egypt. \\ ${ }^{b}$ Chemistry Department, Faculty of Science, Ain Shams University, Cairo, Egypt. \\ Received 3 February 2016, revised 10 May 2016, Accepted 10 June 2016.
}

\begin{abstract}
Regarding to their presence as an important constituent in some ores such as monazite, this work aims for selective solvent extraction of thorium (IV), zirconium (IV), iron (III) and cerium (III) from aqueous sulfate medium using different basic and acidic extractants. To elucidate the extractability of these elements, different effective parameters were studied such as contact time, $\mathrm{pH}$ value, extractant concentration and the diluents type. In a single element system, Th (IV) was extracted by the primary amines (octylamine and tert.octylamine) and the acidic extractnts [di-(2-ethylhexyl) phosphoric acid (D2EHPA) and (bis(2,4,4-trimethyl pentyl) phosphinic acid (Cyanex 272))]. Moreover, secondary amine (N-methylaniline) is effective for Fe (III) extraction while, the primary amines are suitable for $\mathrm{Zr}$ (IV) extraction. Ce (III) can be extracted with the primary amines and D2EHPA. In a mixed elements system, Th (IV) was extracted firstly with Cyanex $272(65 \%)$ at $\mathrm{pH} 1$ followed by the extraction of Fe (III) with $\mathrm{N}$-methylaniline (95\%), then $\mathrm{Zr}$ (IV) was precipitated at $\mathrm{pH} 2.5(84 \%)$ while $\mathrm{Ce}$ (III) remains in the final aqueous phase.
\end{abstract}

KEYWORDS

Solvent extraction, amines, D2EHPA, Cyanex 272.

\section{Introduction}

It is well known that sulfuric acid is the most common acid used for leaching and decomposition of ores and concentrates. One prime example, monazite ore, is a yellow to reddish-brown natural phosphate of the rare earths, mainly the cerium and lanthanum elements, usually with some uranium and thorium. Yttrium, calcium, zirconium, iron and silica are considerably present. ${ }^{1}$ In hydrometallurgical chemistry, several separation techniques were presented like solvent extraction, ion exchange, supported liquid membrane, adsorption, and precipitation methods are very widespread techniques for the extraction and separation of the rare earth elements from various aqueous solutions. ${ }^{2-5}$ One of them, solvent extraction (SX) method has vast range of application in hydrometallurgical separation process due to its great potential on high selectivity, efficient separation and high metal enrichment. ${ }^{2}$ In solvent extraction systems, phosphates, ${ }^{6-8}$ amines $^{9}$ and carboxylic acids ${ }^{10,11}$ solvents are usually studied.

Unfortunately, the presence of iron with a relatively large concentration as an impurity normally associated with REEs in monazite represents a huge problems in the separation of these metals. Iron can be extracted with phosphates, carboxylic acids and amines solvents, but the separation system with phosphates has poor selectivity and the iron-loaded organic phase is complicated to strip. In the carboxylic acid extraction system, carboxylic acids are so easy to dissolve in aqueous phase that the loss of extractant is serious. The extraction system of amines has a higher extraction yield and preferable selectivity when extracting iron. Compared with phosphates, amine systems with iron are easier to be stripped. ${ }^{12,13}$

A literature survey evidence that trioctylamine (TOA) has been

* To whom correspondence should be addressed. E-mail: ashahreldin @yahoo.com used for the separation of $\mathrm{Zr}(\mathrm{IV}) \cdot{ }^{14}$ This method demonstrate the extraction of $\mathrm{Zr}$ (IV) from hydrochloric acid solution with TOA in benzene (nearly $100 \%$ extraction of zirconium at $10^{-2} \mathrm{NHCI}$ with $0.5 \mathrm{M}$ TOA and this is attributed to the presence of the anionic hexachlorozirconate $\left[\mathrm{MCl}_{6}\right]^{2-}$ species and also to the possible formation of $\mathrm{MX}_{4}(\mathrm{TOA})_{2}$ type of complexes). The extraction efficiency is attributed to the chain length of the amine, ${ }^{15}$ in which higher reagent concentrations were required.

Acidic extractant like bis(2-ethyl hexyl)phosphoric acid (D2EHPA) ${ }^{16}$ (bis(2-ethyl hexyl)phosphinic acid (PIA8) have been used for the separation of thorium. The methods employing these extractants have multiple limitations such as high reagent concentration. The potential of Cyanex 272 as an extractant has been well confirmed. The advantages of Cyanex 272 such as its poor aqueous solubility, complete miscibility with common organic diluents and resistance to hydrolysis may be purposive used in commercial processes for isolation of thorium, especially in nuclear energy plan. ${ }^{17-19}$

The solvent extraction of several REEs from sulfate medium has been stated. Notable extractants that have been employed are high molecular weight amines, ${ }^{20}$ carboxylic acids, ${ }^{21}$ tri-n-butyl phosphate (TBP) ${ }^{22}$ and (D2EHPA). ${ }^{23}$ The practical application of the Cyanex reagents group is strongly affected by their deficient extractability and their low loading capacity for REEs resulting from the low lipophilicity of the coordination compounds formed during the extraction process.

The extraction of valuable elements from monazite (such as thorium, zirconium and cerium) with its multicomponent matrix is still a challenging chemical process. So, in the present work, the successive solvent extraction technique was investigated in highly acidic medium which is similar to the acidic conditions that used conventionally for monazite digestion by concen- 
trated sulfuric acid. In view of the above, the current paper has focused to develop a chemical procedure for extraction and subsequent separation of Th (IV), Fe (III), Zr (IV) and Ce (III) from highly acidic sulfate media by various basic and acidic extractants.

\section{Experimental}

\subsection{Chemicals and Reagents}

All chemicals and reagents used were analytical reagent grade. Iron (III) chloride, zirconium oxychloride, thorium nitrate and Cerium chloride heptahydrate were obtained from Sigma Aldrich $(99.9 \%)$ and their standard solutions were prepared in $0.1 \mathrm{M} \mathrm{H}_{2} \mathrm{SO}_{4}$. Octylamine, tert.octylamine, N-methylaniline, $\mathrm{N}, \mathrm{N}$-dimethylaniline, D2EHPA, arsenazo III and Thoron I were supplied by Merck. Cyanex 272 was kindly supplied as a gift by CYTEC Industries (USA). Xylene, petroleum ether, benzene and hexane were obtained from Misr Petroleum Company, Egypt. The $\mathrm{pH}$ of the solutions was readjusted using $0.1 \mathrm{M} \mathrm{HNO}_{3}$ and $0.1 \mathrm{M} \mathrm{NH}_{4} \mathrm{OH}$.

\subsection{Instruments}

All the $\mathrm{pH}$ values of different solutions were measured by using microprocessor-based $\mathrm{pH}$ meter type HANNA (USA) combined with temperature probe. All $\mathrm{pH}$ measurements were done at room temperature $25 \pm 1{ }^{\circ} \mathrm{C}$. All samples in this work were weighed using an analytical balance produced by Bosh (Germany), having maximum sensitivity of $10^{-4} \mathrm{~g}$ and accuracy of $\pm 0.01 \mathrm{mg}$.

\subsection{Spectrophotometric Measurements of Fe (III), $\mathrm{Zr}$ (IV), Th (IV) and Ce (III)}

The concentration of Fe (III), Zr (IV), Th (IV) and Ce (III) in the aqueous phase was determined spectrophotometrically using a Cintra UV-visible spectrophotometer model Cintra 2.2 (Australia).

To avoid the analytical interferences between the investigated elements, each element was measured selectively by the following corresponding method ${ }^{24}$ :

The concentration of Fe (III), Zr (IV), Th (IV) and Ce (III) in the aqueous phase was determined by spectrophotometric thiocyanate (arsenazo III, $\mathrm{HCl}$ ), Thoron I and (arsenazo III, formate buffer) method at the wavelength 495, 665, 540 and $650 \mathrm{~nm}$, respectively.

\subsection{Experimental Procedure}

Six different extractants were dissolved separately in petroleum ether then used for extraction process.

Firstly, different concentrations $\left(10,25,50,75\right.$ and $\left.100 \mathrm{mg} \mathrm{L}^{-1}\right)$ of the investigated elements (Fe (III), Zr (IV), Th (IV) and Ce (III) individually) were prepared in two different media, $0.1 \mathrm{M} \mathrm{H}_{2} \mathrm{SO}_{4}$ and $0.1 \mathrm{M} \mathrm{H}_{3} \mathrm{PO}_{4}$.

Secondly, to avoid the metal hydrolysis, different samples (10 mL each) containing $100 \mathrm{mg} \mathrm{L}^{-1}$ from each element (in distilled water) was prepared individually at different $\mathrm{pH}$ values ranging from 1 to 5 . After 30 min shaking time, the concentrations of each element at each $\mathrm{pH}$ value were measured spectrophotometrically to calculate precipitation percent at each $\mathrm{pH}$ value.

Thirdly, in single element system, equal volumes of the organic phase of the investigated extractants (dissolved in petroleum ether) and the aqueous phase containing $100 \mathrm{mg} \mathrm{L}^{-1}$ of each element (in $0.1 \mathrm{M} \mathrm{H}_{2} \mathrm{SO}_{4}$ ) were shaken individually at different parameters such as contact time, $\mathrm{pH}$ values, extractant concentration and different diluents. The effect of extractant concentration was examined in the range $0.025-0.15 \mathrm{M}$ by mixing $10 \mathrm{~mL}$ of
$100 \mathrm{mg} \mathrm{L}^{-1}$ of each element individual with $10 \mathrm{~mL}$ of different extractant at $\mathrm{pH} 1.5$ and shaken for $45 \mathrm{~min}$ at room temperature. The effect of diluents was examined by mixing $10 \mathrm{~mL}$ of $100 \mathrm{mg}$ $\mathrm{L}^{-1}$ of each element individual with $10 \mathrm{~mL}$ of $0.1 \mathrm{M}$ of different extractant at $\mathrm{pH} 1.5$ and shaken for $45 \mathrm{~min}$, at room temperature.

Finally, for the selective separation of these elements from each other, three different mixed samples were prepared as following:

i. In the first trial, a mixed sample $(75 \mathrm{~mL})$ contains $100 \mathrm{mg} \mathrm{L}^{-1}$ of each element was prepared in $0.1 \mathrm{M} \mathrm{H}_{2} \mathrm{SO}_{4}$ (original solution $\mathrm{pH}$ was 1.5), the $\mathrm{pH}$ was adjusted to 1 (to be similar to monazite medium after digestion with sulfuric acid) using $0.1 \mathrm{MHNO}_{3}$. In the first cycle, the sample was mixed with the organic phase (0.1 M N-methylaniline) and shaken for 60 min, at room temperature. After the separation of the two phases, $10 \mathrm{~mL}$ (F1) from the aqueous phase was taken for the spectrophotometric measurements. The remaining aqueous phase was readjusted to $\mathrm{pH} 1$ using $0.1 \mathrm{M} \mathrm{NH}_{4} \mathrm{OH}$, then mixed in the second cycle with the organic phase $(0.1 \mathrm{M}$ Cyanex 272) and shaken for $60 \mathrm{~min}$ at room temperature. After the separation of the two phases, $10 \mathrm{~mL}$ (F2) from the aqueous phase was taken for the measurements. The remaining aqueous phase was readjusted to $\mathrm{pH} 2.5 \mathrm{using} 0.1 \mathrm{M}$ $\mathrm{NH}_{4} \mathrm{OH}$, and then filtrated to separate the formed precipitate. $10 \mathrm{~mL}$ (F3) from the filtrated aqueous phase was taken for measurements.

ii. In the second trial, a mixed sample $(50 \mathrm{~mL})$ contains $100 \mathrm{mg}$ $\mathrm{L}^{-1}$ of $\mathrm{Zr}$ (IV), Th (IV) and Ce (III) (without Fe (III)) was prepared in $0.1 \mathrm{MH}_{2} \mathrm{SO}_{4}$, then the $\mathrm{pH}$ was adjusted to $1 \mathrm{using}$ $0.1 \mathrm{MHNO}_{3}$. In the first cycle, the sample was mixed with the organic phase (0.1 M Cyanex 272) and shaken for $60 \mathrm{~min}$ at room temperature. After the separation of the two phases, $10 \mathrm{~mL}$ (F1) from the aqueous phase was taken for measurements. The remaining aqueous phase was readjusted to $\mathrm{pH}$ 2.5 using $0.1 \mathrm{M} \mathrm{NH}_{4} \mathrm{OH}$, and then filtrated to separate the formed precipitate. $10 \mathrm{~mL}(\mathrm{~F} 2)$ from the aqueous filtrated phase was taken for measurements.

iii. In the third trial, a mixed sample $(75 \mathrm{~mL})$ contain $100 \mathrm{mg} \mathrm{L}^{-1}$ from each element was prepared in $0.1 \mathrm{M} \mathrm{H}_{2} \mathrm{SO}_{4}$, then the $\mathrm{pH}$ was adjusted to 1 using $0.1 \mathrm{M} \mathrm{HNO}_{3}$. In the first cycle, the sample was mixed with the organic phase (0.1 M Cyanex 272) and shaken for $60 \mathrm{~min}$ at room temperature. After the separation of the two phases, $10 \mathrm{~mL}$ (F1) from the aqueous phase was taken for measurements. The remaining aqueous phase was readjusted to $\mathrm{pH} 1$ using $0.1 \mathrm{M} \mathrm{NH}_{4} \mathrm{OH}$, then mixed in the second cycle with the organic phase $(0.1 \mathrm{M} \mathrm{N}$-methylaniline) and shaken for $60 \mathrm{~min}$ at room temperature. After the separation of the two phases, $10 \mathrm{~mL}$ (F2) from the aqueous phase was taken for measurements. The remaining aqueous phase was readjusted to $\mathrm{pH} 2.5$ using $0.1 \mathrm{M}$ $\mathrm{NH}_{4} \mathrm{OH}$, and then filtrated. $10 \mathrm{~mL}$ (F3) from the aqueous phase was taken for measurements.

To choose the suitable stripping agent for Th (IV) and Fe (III), the organic phase of the first and second cycles were shaken with different concentrations of $\mathrm{HCl}$ and $\mathrm{HNO}_{3}$ in the range $(1.0-5.0 \mathrm{M})$ with an $\mathrm{A} / \mathrm{O}$ phase ratio of $1: 1$, at equilibration time of $20 \mathrm{~min}$, and at room temperature.

The metal extraction (\%) at any instant time was determined by the following equation:

Extraction $(\%)=\left[\left(C_{o}-C_{e}\right) / C_{o}\right] \times 100$

where $C_{o}$ is the initial concentration of metal ions and $C_{e}$ is the concentration of metal ions in the aqueous solution after extraction process.

All the previous experimental work was repeated two times 
(duplicated) only due to the high cost of the chemicals and extractant.

\section{Results and Discussion}

\subsection{Effect of Medium}

Monazite ore processing is a complicated matrix which is mainly attributed to the presence of high phosphate $(25 \%$ of $\mathrm{P}_{2} \mathrm{O}_{5}$ ) and sulfate concentration ${ }^{25}$ hence, influence the extraction and separation of REEs and other elements. Therefore, the effect of medium on the presence of the investigated elements was studied individually in sulfate and phosphate media using $0.1 \mathrm{M}$ $\mathrm{H}_{2} \mathrm{SO}_{4}$ and $0.1 \mathrm{M} \mathrm{H}_{3} \mathrm{PO}_{4}$. As shown in Table 1, by measuring the absorbance value of each concentration of each element in each medium, it's clear that the absorbance value of Fe (III) and Ce (III) is significantly suppressed in phosphate medium rather than the corresponding values in sulfate medium. Furthermore, $\mathrm{Zr}$ (IV) and Th (IV), are completely precipitate in phosphate medium even at low element concentration $\left(10 \mathrm{mg} \mathrm{L}^{-1}\right)$.

So, it is recommended to eliminate the phosphate ions before separation and extraction of these elements, especially Zr (IV) and Th (IV). To avoid the matrix complication, many trials to separate phosphate ions have been previously published in the literature. . 2,27

Based on the previously obtained results, all of the following experiments were carried out in sulfate medium $\left(0.1 \mathrm{M} \mathrm{H}_{2} \mathrm{SO}_{4}\right)$.

Table 1 Effect of sulfate and phosphate medium on the absorbance value of metal ions.

\begin{tabular}{|c|c|c|c|}
\hline \multirow{2}{*}{\multicolumn{2}{|c|}{$\begin{array}{l}\text { Metal ion concentration } \\
\qquad / \mathrm{mg} \mathrm{L}^{-1}\end{array}$}} & \multicolumn{2}{|c|}{ Absorbance value } \\
\hline & & \multirow{2}{*}{$\begin{array}{c}0.1 \mathrm{M} \mathrm{H}_{2} \mathrm{SO}_{4} \\
0.166 \pm 0.005\end{array}$} & \multirow{2}{*}{$\begin{array}{r}0.1 \mathrm{M} \mathrm{H}_{3} \mathrm{PO}_{4} \\
0.05 \pm 0.003\end{array}$} \\
\hline Fe (III) & 10 & & \\
\hline & 25 & $0.365 \pm 0.01$ & $0.14 \pm 0.007$ \\
\hline & 50 & $0.749 \pm 0.033$ & $0.36 \pm 0.016$ \\
\hline & 75 & $1.1 \pm 0.038$ & $0.57 \pm 0.023$ \\
\hline & 100 & $1.43 \pm 0.072$ & $0.62 \pm 0.31$ \\
\hline \multirow[t]{5}{*}{$\mathrm{Zr}(\mathrm{IV})$} & 10 & $0.52 \pm 0.023$ & Zero \\
\hline & 25 & $0.605 \pm 0.021$ & Zero \\
\hline & 50 & $0.667 \pm 0.04$ & Zero \\
\hline & 75 & $0.706 \pm 0.031$ & Zero \\
\hline & 100 & $0.721 \pm 0.036$ & Zero \\
\hline \multirow[t]{5}{*}{ Th (IV) } & 10 & $0.157 \pm 0.006$ & Zero \\
\hline & 25 & $0.434 \pm 0.017$ & Zero \\
\hline & 50 & $0.876 \pm 0.035$ & Zero \\
\hline & 75 & $0.99 \pm 0.034$ & $0.0025 \pm 0.0001$ \\
\hline & 100 & $0.99 \pm 0.032$ & $0.01 \pm 0.0004$ \\
\hline \multirow[t]{5}{*}{$\mathrm{Ce}$ (III) } & 10 & $0.064 \pm 0.003$ & $0.034 \pm 0.0017$ \\
\hline & 25 & $0.246 \pm 0.012$ & $0.105 \pm 0.005$ \\
\hline & 50 & $0.594 \pm 0.027$ & $0.157 \pm 0.008$ \\
\hline & 75 & $0.88 \pm 0.044$ & $0.295 \pm 0.017$ \\
\hline & 100 & $1.12 \pm 0.056$ & $0.299 \pm 0.015$ \\
\hline
\end{tabular}

\subsection{Metal Hydrolysis Process}

The extraction processes of the investigated elements by different extractants are mainly affected by the side reaction that may be due to the metal hydrolysis which mainly depends on solution $\mathrm{pH}$. In this respect, series of experiments have been tested separately to evaluate the degree of contribution of each of the two opposite reaction mechanisms (extraction vs. precipitation).

The results for metal hydrolysis of $100 \mathrm{mg} \mathrm{L}^{-1}$ from each element are shown in Table 2. It can be seen that both of Fe (III) and $\mathrm{Zr}$ (IV) starting hydrolysis at $\mathrm{pH} 2$, while Th (IV) and Ce (III) started to precipitate at $\mathrm{pH} 3$.

According to metal hydrolysis results, all the next experiments were carried out at $\mathrm{pH} 1.5$ to avoid the hydrolysis of the metal ions and to be similar to the acidic conditions which conventionally used for monazite digestion by sulfuric acid.

\subsection{Effect of Contact Time}

One of the main factors affecting the separation and extraction processes is the contact time. The effect of the contact time was studied by mixing $10 \mathrm{~mL}$ of $100 \mathrm{mg} \mathrm{L}^{-1}$ of each element individually at $\mathrm{pH} 1.5$ with $10 \mathrm{~mL}$ of the organic phase containing $0.1 \mathrm{M}$ of the investigated extractants and shaked at different times at room temperature. According to Fig. 1, it was observed that:

i. N-methylaniline preferably extracts Fe (III).

ii. Octylamine preferably extracts $\mathrm{Zr}$ (IV), Th (IV) and Ce (III). iii. Cyanex 272 is selective extractant for separation of Th (IV). iv. D2EHPA preferably extracts both of Th (IV) and Ce (III).

The solvent extraction of $\mathrm{Zr}$ (IV) with Cyanex 272, Cyanex 302 and Cyanex $301,{ }^{28}$ from sulfuric acid solutions has been examined systematically. However, the reagents show poor selectivity. $\mathrm{Zr}$ (IV) was efficiently extracted from nitric and hydrochloric acid solution with tri- $n$-butyl phosphate (TBP) in kerosene. ${ }^{29}$ In the present work, Zr (IV) was effectively extracted from sulfuric acid solutions with octylamine or tert.octylamine in petroleum ether.

The revealed data for Th (IV) extraction was in a good agreement with many previously published papers. For instance, Eskandari Nasab et al..$^{30}$ reported that Th (IV) was extracted from $0.01 \mathrm{M}$ nitric acid solution by Cyanex 272 in kerosene. Also, the extraction of Th (IV) from aqueous sulphuric acid medium with a synergistic mixture of $\mathrm{N}$-n-octylaniline and trioctylamine (TOA) in xylene was investigated by Patkar et al. ${ }^{31}$ According to Borai et al., ${ }^{32}$ in sulfate medium, thorium is extracted preferably by primary amines. The proposed mechanism for Th (IV) extraction by amines was illustrated in equation (2) by Shimidt: ${ }^{33}$

$$
\begin{aligned}
& 4 \mathrm{RNH}_{2} \mathrm{H}^{+} \mathrm{HSO}_{4}^{-}{ }_{(\mathrm{org})}+\left[\mathrm{Th}\left(\mathrm{SO}_{4}\right)_{4}\right]^{4-}{ }_{(\mathrm{aq})}= \\
& \left(\mathrm{RNH}_{2} \mathrm{H}^{+}\right)_{4}\left[\mathrm{Th}\left(\mathrm{SO}_{4}\right)_{4}\right]^{4-}{ }_{(\text {org })}+4 \mathrm{HSO}_{4}^{-}{ }_{(\mathrm{aq})}
\end{aligned}
$$

For Ce (III) extraction, the obtained results are in a good agreement with many previously published results. According to Kim et al., ${ }^{34}$ zero percent extraction was observed for all rare-earth elements at all $\mathrm{pH}$ values tested using $1 \mathrm{M}$ Alamine 336 (tertiary amine) or Aliquat 336 (quaternary ammonium salt). Similarly, Amaral et al. ${ }^{35}$ proved that Primene JM-T (primary amine) can

\begin{tabular}{|c|c|c|c|c|c|c|c|c|}
\hline \multirow[b]{2}{*}{ Elements } & \multicolumn{8}{|c|}{$\mathrm{pH}$ values } \\
\hline & 1 & 1.5 & 2 & 2.5 & 3 & 3.5 & 4 & 5 \\
\hline $\mathrm{Fe}(\mathrm{III})$ & Zero & Zero & $27 \pm 3$ & $56 \pm 2.8$ & $83 \pm 3.5$ & 100 & 100 & 100 \\
\hline $\mathrm{Zr}$ (IV) & Zero & Zero & $34 \pm 2.4$ & $62 \pm 2.9$ & $89 \pm 3$ & 100 & 100 & 100 \\
\hline Th (IV) & Zero & Zero & Zero & Zero & $22 \pm 3.2$ & $37 \pm 1.9$ & $51 \pm 2.4$ & $82 \pm 2.2$ \\
\hline Ce (III) & Zero & Zero & Zero & Zero & $18 \pm 2.7$ & $29 \pm 2.2$ & $42 \pm 2.7$ & $76 \pm 2.3$ \\
\hline
\end{tabular}

Table 2 Metal hydrolysis (\%) at different $\mathrm{pH}$ values. 
extract REEs. Thus, REEs can be extracted by primary amines not by secondary or tertiary amines. Moreover, the extraction of some REEs from chloride medium using a mixture of 2-ethylhexylphosphonic mono-2-ethylhexyl ester (HEHEHP) and (D2EHPA) was achieved by Fengyun Zhang et al. ${ }^{36}$ Although Cyanex 272 was used for the separation of some REEs from chloride medium, ${ }^{34}$ the extraction behavior of Ce (III) with Cyanex 272 from sulfate medium was negative as demonstrated in the present work.

\subsection{Effect of $\mathrm{pH}$}

An important variable affecting the separation percent is the $\mathrm{pH}$ of the aqueous solution. The effect of $\mathrm{pH}$ was examined by mixing $10 \mathrm{~mL}$ of $100 \mathrm{mg} \mathrm{L}^{-1}$ from each element individual at different $\mathrm{pH}$ values with $10 \mathrm{~mL}$ of the organic phase containing $0.1 \mathrm{M}$ of the investigated extractants and shaken for $45 \mathrm{~min}$, and at room temperature. Figure 2 showed that:

i. Both of Fe (III) and Th (IV) can be extracted at pH 1 and 1.5 with N-methylaniline and Cyanex 272, respectively.

ii. $\mathrm{Zr}(\mathrm{IV})$ can be extracted at $\mathrm{pH} 1.5$ with octylamine while at $\mathrm{pH} 2, \mathrm{Zr}$ (IV) is hydrolyzed as illustrated in Table 2.

iii. Ce (III) can be extracted at both $\mathrm{pH} 1.5$ and 2 with octylamine, tert.octylamine and D2EHPA. Moreover, octylamine has the
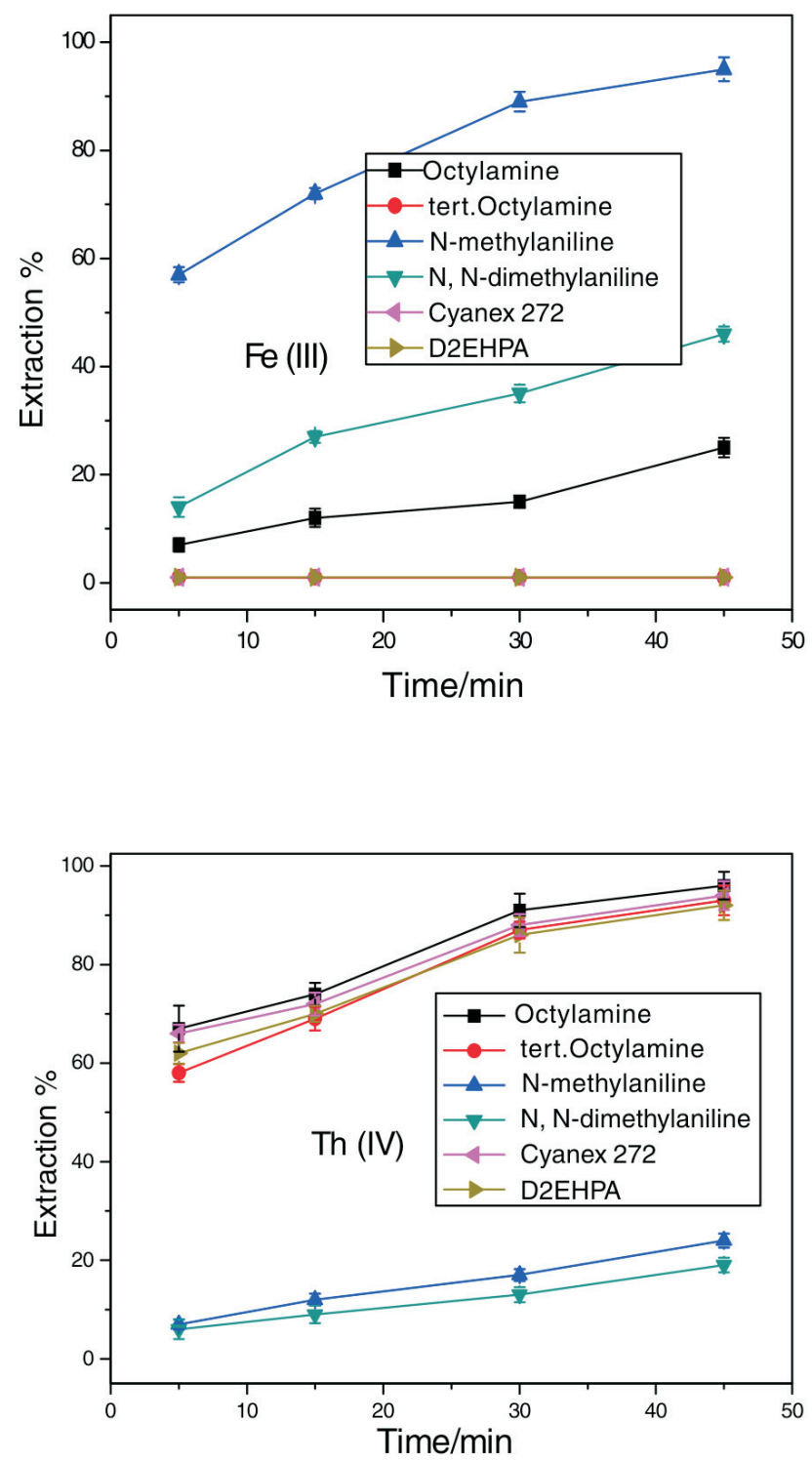

higher extraction efficiency than tert.octylamine and D2EHPA.

\subsection{Effect of Extractant Concentration}

The concentration of extractants is one of the operating parameters that significantly influence the final recovery process of the investigated elements. It is clear from Fig. 3 that, the extraction efficiency of the investigated elements increases when increasing the extractant concentration and reached to equilibrium at $0.1 \mathrm{M}$ of extractant. Further increase in extractant concentration leads to insignificant improvement in the metal extraction efficiency. So, the extraction efficiency of the investigated elements was optimized at the following condition:

i. Fe (III) preferably extracted with $\mathrm{N}$-methylaniline.

ii. $\mathrm{Zr}$ (IV) can be extracted either with octylamine or tert.octylamine with almost the same efficiency.

iii. Th (IV) can be extracted with octylamine or tert.octylamine or Cyanex 272 or D2EHPA, nearly with the same efficiency.

iv. Ce (III) can be extracted with octylamine or tert.octylamine or D2EHPA, nearly with the same efficiency.

\subsection{Effect of Diluents}

Diluents influence the extraction of metals by amines and acids
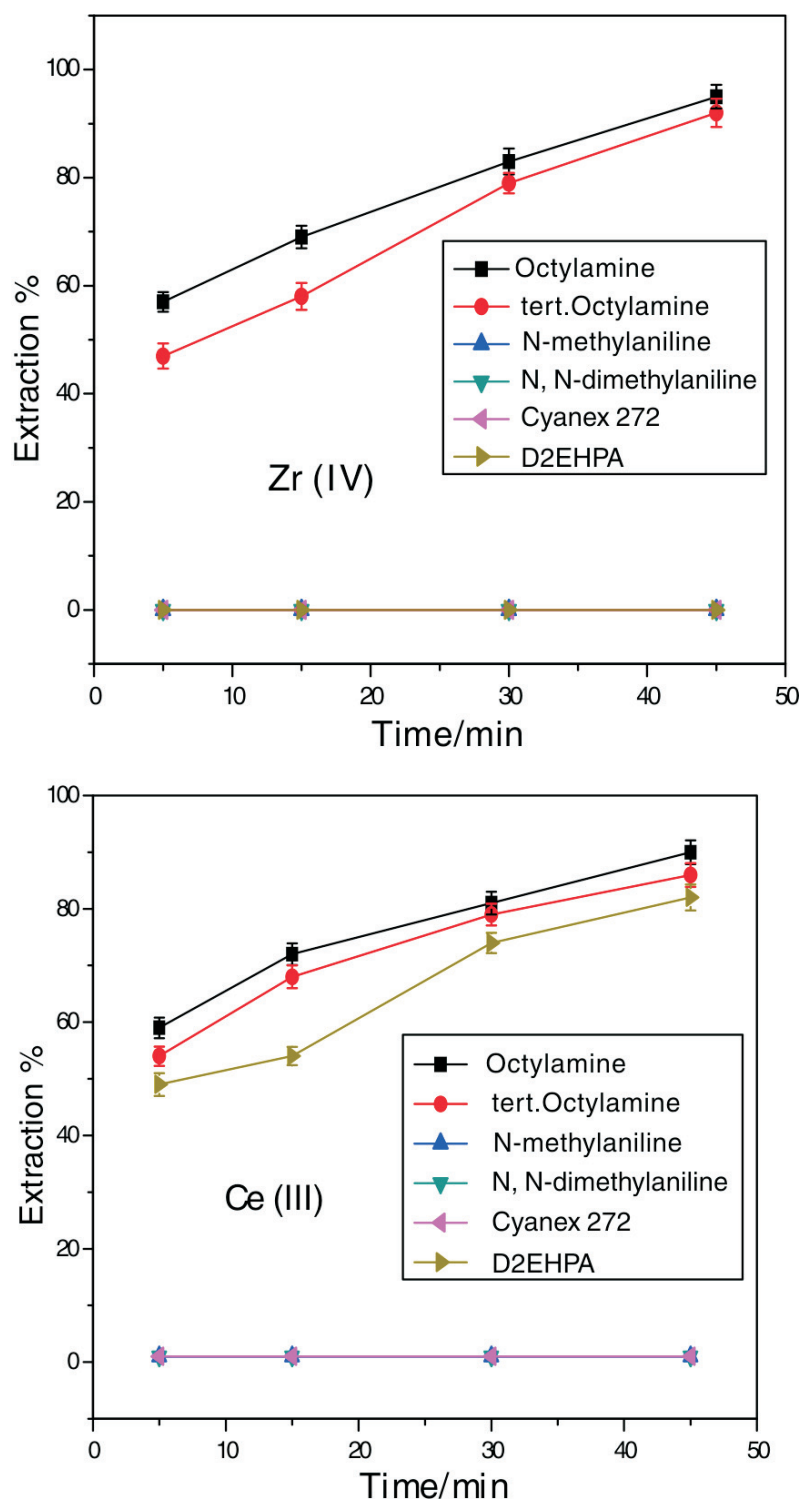

Figure 1 Effect of contact time on the extraction \% of Fe (III), Zr (IV), Th (IV) and Ce (III) from sulfate medium. 
due to the aggregation of them in the organic phase. ${ }^{37}$ Therefore, various aromatic and aliphatic solvents with different dielectric constants were tested as diluents for the extraction of the investigated elements as shown in Table 3 . The results obtained in Table 4 showed that both of petroleum ether and hexane are preferred for the extraction process, while xylene and benzene proved to be poor diluents. It was reported that there is a good correlation between the effect of a diluent and its dielectric constant. $^{38}$ The diluents should have a low dielectric constant and weak hydrogen bonding capacity. Owing to several factors like cost, environmental and safety aspects and maximum extraction efficiency, aliphatic petroleum ether was preferred as the diluent for all the experimental work.

Depending on the previously obtained results, it was concluded that:

i. N-methylaniline is selective extractant for separation of Fe (III) at pH 1.
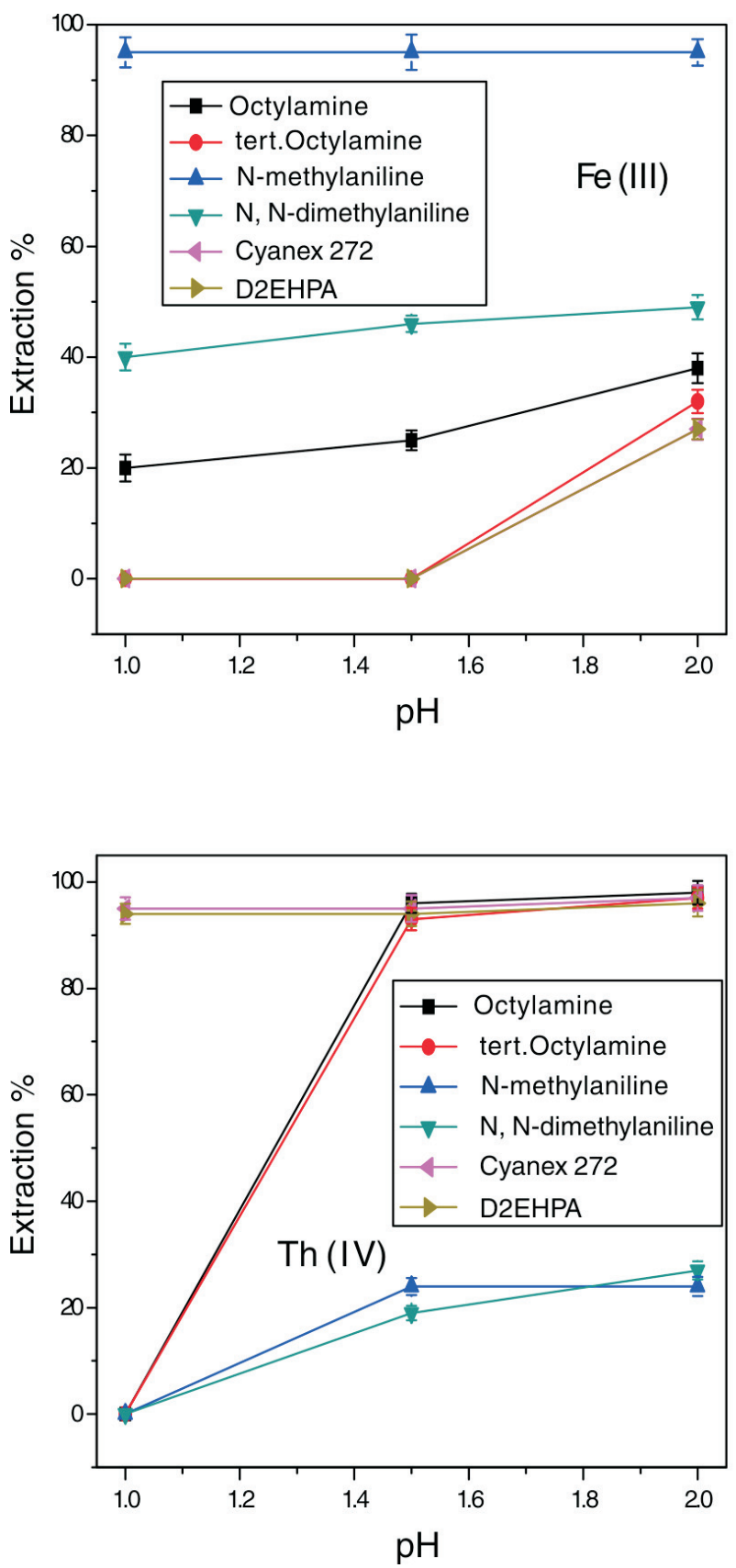

ii. Cyanex 272 is selective extractant for separation of Th (IV) at $\mathrm{pH} 1$.

iii. $\mathrm{Zr}$ (IV) can be efficiently precipitated at $\mathrm{pH}$ 2.5.

iv. Ce (III) can be separated at pH 1.5 with octylamine or D2EHPA.

\subsection{Selective Separation of Fe (III), Zr (IV), Th (IV) and \\ Ce (III) from a Synthetic Mixture}

Series of experiments were attempts to separate Fe (III), Zr (IV), Th (IV) and Ce (III) from each other in a multielements mixed solution. These experiments were performed based on the previously optimized conditions for extraction of each element. Three mixed samples of the investigated elements were prepared to examine the effect of each element on the extraction and separation of the other three elements.

i. In the first mixed sample, the proposed processes were aimed to separate Fe (III) in the first extraction cycle followed
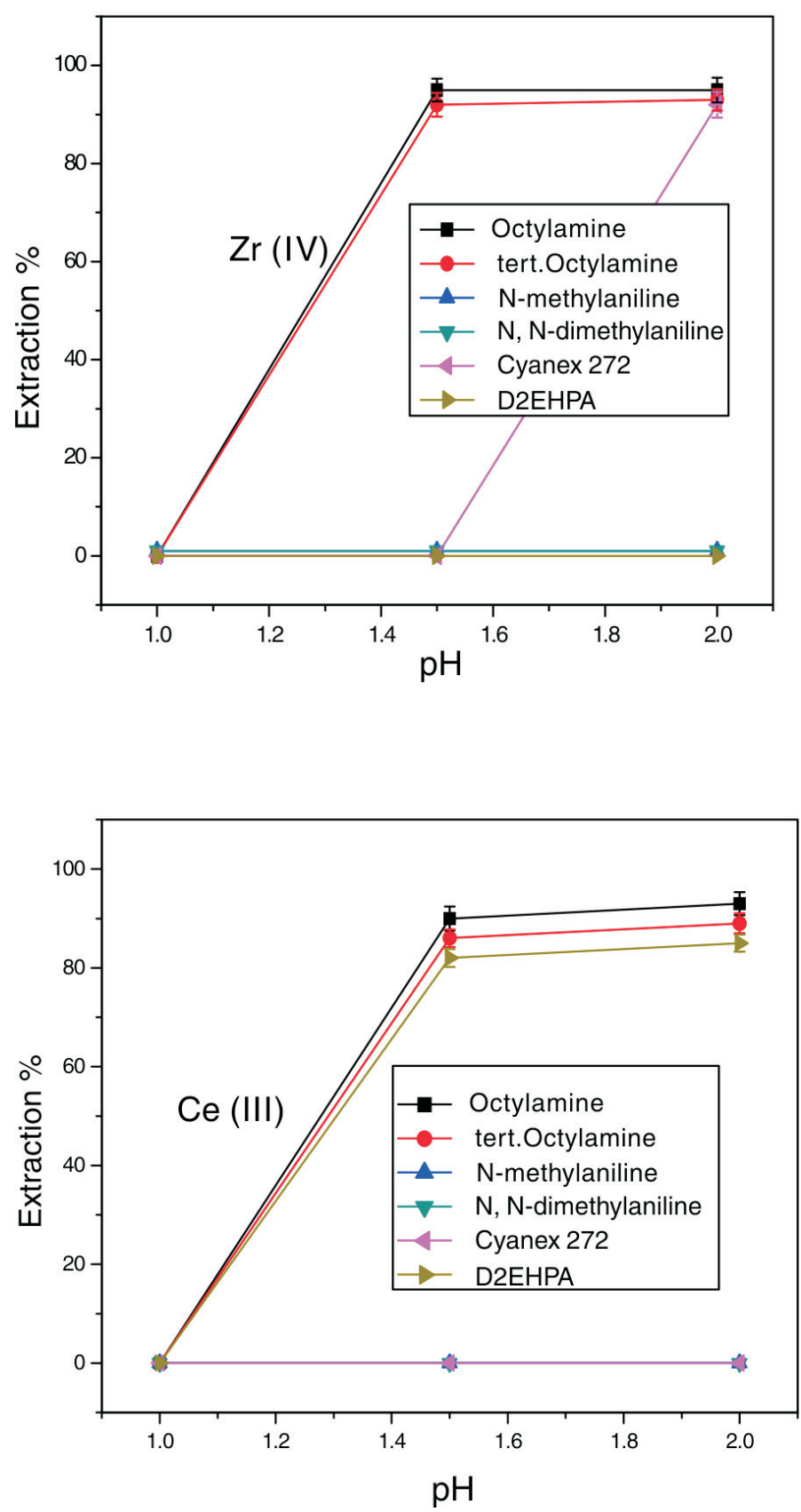

Figure 2 Effect of $\mathrm{pH}$ on the extraction \% of Fe (III), Zr (IV), Th (IV) and Ce (III) from sulfate medium. 

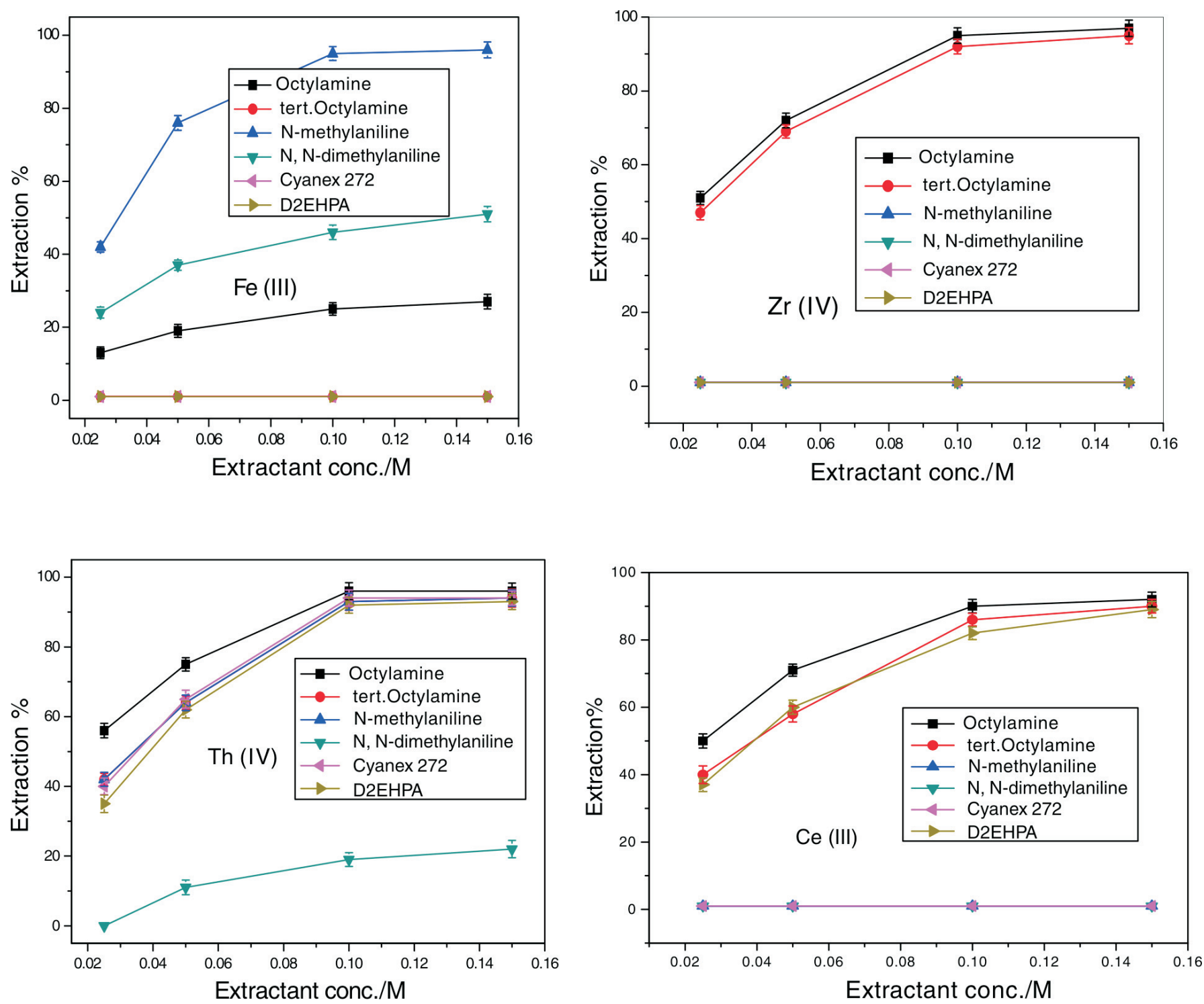

Figure 3 Effect of extractant concentration on the extraction efficiency of the elements.

by separation of Th (IV) in the second extraction cycle followed by precipitation of $\mathrm{Zr}$ (IV) while Ce (III) remains in the aqueous solution.

The data represented in Table 5 showed that, Fe (III) in F1 (first cycle) could be efficiently and selectively separated (95\%) at $\mathrm{pH}$ 1 with $\mathrm{N}$-methylaniline. This result is in a good agreement with the previously individual results obtained. In F2 (second cycle), it was expected to separate Th (IV) at $\mathrm{pH} 1$ with Cyanex 272 but unfortunately it does not extract. In F3 (third cycle), the $\mathrm{pH}$ was adjusted to 2.5 , to precipitate $\mathrm{Zr}$ (IV) (87\%). Finally, Th (IV) and $\mathrm{Ce}$ (III) are overlapped and remained in the aqueous solution.

ii. The second mixed sample was prepared in the absence of Fe

(III) to examine its effect on the extraction of other elements.

Table 3 Dielectric constant of the investigated diluents.

\begin{tabular}{lc}
\hline Diluents & Dielectric constant \\
\hline Petroleum ether & 2 \\
Hexane & 2.02 \\
Xylene & 2.28 \\
Benzene & 2.3 \\
\hline
\end{tabular}

The proposed process was aimed to separate Th (IV) in the first cycle followed by precipitation of $\mathrm{Zr}$ (IV) while Ce (III) remains in the aqueous solution.

The data presented in Table 6 showed that, Th (IV) in F1 (first cycle) could be efficiently separated $(92 \%)$ at $\mathrm{pH} 1$ with Cyanex 272. This result is in a good agreement with the previously individual results obtained. In F2 (second cycle), the $\mathrm{pH}$ was adjusted to 2.5. In this case $\mathrm{Zr}$ (IV) was precipitated $(87 \%)$ and Ce (III) remains in the aqueous solution.

iii. In the third mixed sample, the proposed process was aimed to separate Th (IV) in the first cycle followed by separation of Fe (III) in the second cycle, followed by precipitation of $\mathrm{Zr}$ (IV) while Ce (III) remains in the aqueous solution.

The data presented in Table 7 showed that, Th (IV) in F1 (first cycle) could be efficiently separated $(65 \%)$ at $\mathrm{pH} 1$ with Cyanex 272 which in a good agreement with the previously individual results obtained. In F2 (second cycle), Fe (III) was separated at pH1 with N-methylaniline (95\%). In F3 (third cycle), the $\mathrm{pH}$ was adjusted to 2.5 to precipitate $\mathrm{Zr}$ (IV) with high uptake $84 \%$. The precipitation efficiency was improved from $62 \%$ in aqueous medium to $84 \%$ in sulfate medium. This may be due the formation of less soluble $\mathrm{Zr}$ (IV)-sulfate complex which is more easily 
Table 4 Effect of diluents on the extraction (\%) of Fe (III), Zr (IV), Th (IV) and Ce (III).

\begin{tabular}{|c|c|c|c|c|c|c|c|c|}
\hline \multirow{2}{*}{$\begin{array}{l}\text { Diluents: } \\
\text { Extractant }\end{array}$} & \multicolumn{4}{|c|}{ Xylene } & \multicolumn{4}{|c|}{ Petroleum ether } \\
\hline & Fe (III) & Th (IV) & $\mathrm{Zr}(\mathrm{IV})$ & Ce (III) & $\mathrm{Fe}(\mathrm{III})$ & Th (IV) & $\mathrm{Zr}(\mathrm{IV})$ & Ce (III) \\
\hline Octylamine & $15 \pm 2.3$ & $59 \pm 2.5$ & $54 \pm 2.1$ & $54 \pm 2$ & $25 \pm 3$ & $96 \pm 2.9$ & $95 \pm 2.8$ & $90 \pm 3.4$ \\
\hline tert.octylamine & Zero & $48 \pm 1.9$ & $49 \pm 2$ & $47 \pm 1.8$ & Zero & $93 \pm 3.2$ & $92 \pm 2.6$ & $86 \pm 2.4$ \\
\hline N-Methylaniline & $44 \pm 2.3$ & $14 \pm 2.3$ & Zero & Zero & $95 \pm 2.7$ & $24 \pm 2.9$ & Zero & Zero \\
\hline $\mathrm{N}, \mathrm{N}$-Dimethylaniline & $27 \pm 2.7$ & $8 \pm 3$ & Zero & Zero & $46 \pm 3.4$ & $19 \pm 2.3$ & Zero & Zero \\
\hline Cyanex 272 & Zero & $42 \pm 1.8$ & Zero & Zero & Zero & $94 \pm 2.9$ & Zero & Zero \\
\hline \multirow[t]{3}{*}{ D2EHPA } & Zero & $40 \pm 3$ & Zero & $41 \pm 2.5$ & Zero & $92 \pm 2.1$ & Zero & $82 \pm 2.6$ \\
\hline & \multicolumn{4}{|c|}{ Hexane } & \multicolumn{4}{|c|}{ Benzene } \\
\hline & $\mathrm{Fe}$ (III) & Th (IV) & $\mathrm{Zr}(\mathrm{IV})$ & Ce (III) & $\mathrm{Fe}$ (III) & Th (IV) & $\mathrm{Zr}(\mathrm{IV})$ & $\mathrm{Ce}$ (III) \\
\hline Octylamine & $24 \pm 1.9$ & $85 \pm 2.3$ & $86 \pm 2.7$ & $84 \pm 2.4$ & $10 \pm 1.5$ & $42 \pm 2.1$ & $41 \pm 1.9$ & $39 \pm 1.8$ \\
\hline tert.octylamine & Zero & $82 \pm 2.8$ & $78 \pm 2.6$ & $80 \pm 2.1$ & Zero & $34 \pm 2.3$ & $38 \pm 2.4$ & $31 \pm 2$ \\
\hline N-Methylaniline & $81 \pm 3$ & $22 \pm 2.7$ & Zero & Zero & $25 \pm 1.6$ & $11 \pm 2$ & Zero & Zero \\
\hline $\mathrm{N}, \mathrm{N}$-Dimethylaniline & $38 \pm 3.2$ & $11 \pm 2.9$ & Zero & Zero & $13 \pm 2.7$ & Zero & Zero & Zero \\
\hline Cyanex 272 & Zero & $82 \pm 2.2$ & Zero & Zero & Zero & $39 \pm 1.4$ & Zero & Zero \\
\hline D2EHPA & Zero & $85 \pm 2.7$ & Zero & $78 \pm 2.8$ & Zero & $36 \pm 2$ & Zero & $29 \pm 2.5$ \\
\hline
\end{tabular}

precipitated. Finally, Ce (III) was remained in the aqueous solution.

Finally, the recommended subsequent selective extraction for separation process of Fe (III), Zr (IV), Th (IV) and Ce (III) from aqueous sulfate medium is presented in Fig. 4 .

Table 5 Extraction \% in the first mixed sample.

\begin{tabular}{lcccc}
\hline & \multicolumn{4}{c}{ Extraction \% } \\
\cline { 2 - 5 } Sample & Fe (III) & Th (IV) & Zr (IV) & Ce (III) \\
\hline F1 (first cycle) & $95 \pm 2.7$ & Zero & Zero & Zero \\
F2 (second cycle) & Zero & Zero & Zero & Zero \\
F3 (third cycle) & Zero & Zero & $87 \pm 2.4$ & Zero \\
\hline
\end{tabular}

Table 6 Extraction \% in the second mixed sample.

\begin{tabular}{lccc}
\hline & \multicolumn{3}{c}{ Extraction $\%$} \\
\cline { 2 - 4 } Sample & Th (IV) & Zr (IV) & Ce (III) \\
\hline F1 & $92 \pm 2.8$ & Zero & Zero \\
F2 & Zero & $87 \pm 2.5$ & Zero \\
\hline
\end{tabular}

Table 7 Extraction \% in the third mixed sample.

\begin{tabular}{lcccc}
\hline \multirow{4}{*}{ Sample } & \multicolumn{4}{c}{ Extraction \% } \\
\cline { 2 - 5 } & Th (IV) & Fe (III) & Zr (IV) & Ce (III) \\
\hline F1 & $65 \pm 2.8$ & Zero & Zero & Zero \\
F2 & $7 \pm 3$ & $95 \pm 2$ & Zero & Zero \\
F3 & $12 \pm 2.4$ & Zero & $84 \pm 2.9$ & Zero \\
\hline
\end{tabular}

\subsection{Comparison}

The obtained results were compared with other previously published results as demonstrated in Table 8.

The results in Table 8 showed that the proposed procedure has higher extraction \% comparing with others. Furthermore, the proposed procedure could be applied for separation of Th (IV), Fe (III), Zr (IV) and Ce (III) from highly acidic sulfate medium.

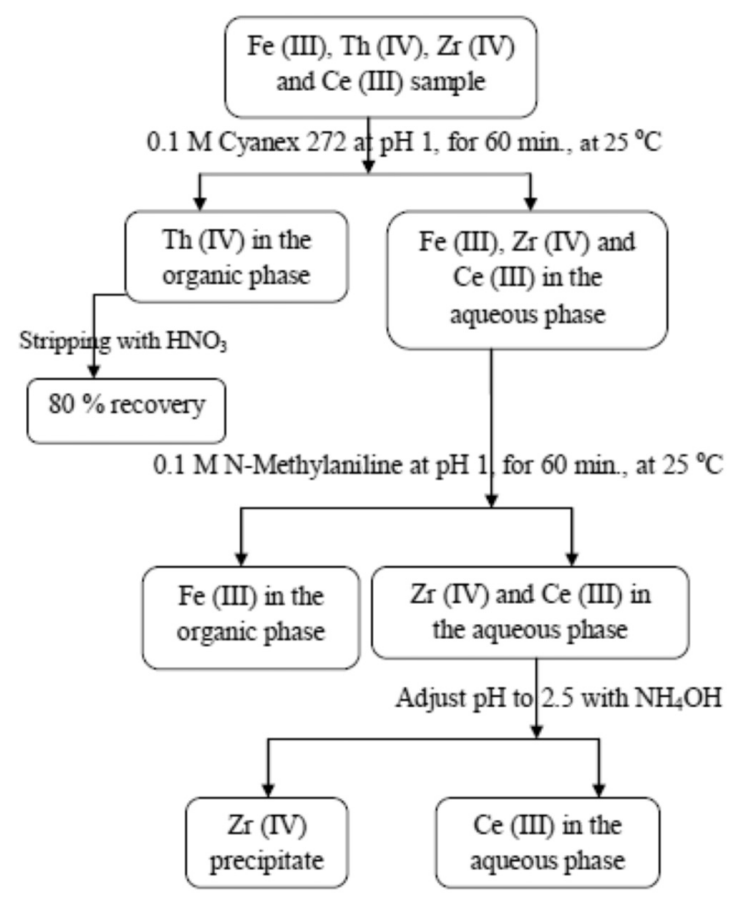

Figure 4 Flowchart for subsequent selective separation of Fe (III), Zr (IV), Th (IV) and Ce (III) from the acidic sulfate solution.

Table 8 Comparison with some previous studies.

\begin{tabular}{lcccc}
\hline Studies & Element & Extractant & {$\left[\mathrm{H}^{+}\right]$} & Extraction $\%$ \\
\hline${\text { Eskandari } \text { et al }^{30}}_{\text {I.M. Ahmed }^{39}}$ & $\mathrm{Th}(\mathrm{IV})$ & Cyanex 302 & $5 \mathrm{M} \mathrm{H}_{2} \mathrm{SO}_{4}$ & 47.7 \\
Present study & $\mathrm{Fe}(\mathrm{III})$ & Cyanex 272 & $\mathrm{pH} \mathrm{2.5}$ & 80 \\
& $\mathrm{Th}(\mathrm{IV})$ & Cyanex 272 & $\mathrm{pH} 1$ & 65 \\
& $\mathrm{Fe}(\mathrm{III})$ & N-methylaniline & $\mathrm{pH} 1$ & 95 \\
\hline
\end{tabular}




\subsection{Stripping of Th (IV) and Fe (III)}

Stripping of Th (IV) and Fe (III) from the organic phase using different concentration of inorganic acid such as $\mathrm{HCl}$ and $\mathrm{HNO}_{3}$ has been tested. As shown in Table $9,80 \%$ of Th (IV) was efficiently stripped by $4 \mathrm{MHCl}$ while, $\mathrm{Fe}$ (III) was not stripped by the two tested acids even at $5.0 \mathrm{M}$. According to Lasheen et al. ${ }^{40}$ and Li et al..$^{41}$ the extraction of iron (III) with some amines is accompanied by the formation of the third phase between organic and aqueous phase. Therefore, it was necessary to add a modifier during the extraction step to improve the stripping of iron.

Table 9 Stripping \% for Th (IV) and Fe (III) from the organic phase.

Stripping agent Stripping \% for Th (IV) Stripping \% for Fe (III)

\begin{tabular}{lll}
\hline $1-5 \mathrm{M} \mathrm{HNO}_{3}$ & Zero & Zero \\
$1 \mathrm{M} \mathrm{HCl}$ & $15 \pm 2.8$ & Zero \\
$2 \mathrm{M} \mathrm{HCl}$ & $32 \pm 3$ & Zero \\
$3 \mathrm{M} \mathrm{HCl}$ & $55 \pm 2.6$ & Zero \\
$4 \mathrm{M} \mathrm{HCl}$ & $80 \pm 1.9$ & Zero \\
$5 \mathrm{M} \mathrm{HCl}$ & $80 \pm 2.1$ & Zero \\
\hline
\end{tabular}

\section{Conclusion}

Subsequent and selective solvent extraction of Fe (III), Zr (IV), $\mathrm{Th}$ (IV) and Ce (III) from the acidic sulfate solution with different basic and acidic extractant in petroleum ether has been successfully developed. The developed procedure clearly demonstrate the superiority of Cyanex 272 and N-methylaniline to separate $\mathrm{Th}$ (IV) and Fe (III) respectively at $\mathrm{pH} 1$ followed by the precipitation of $\mathrm{Zr}$ (IV) at $\mathrm{pH}$ 2.5. Meanwhile Ce (III) remains in the aqueous solution.

\section{Acknowledgement}

Authors are thankful to the Science and Technology Development Fund (STDF), Egypt, for the financial support, Grant No 5021.

\section{References}

1 Y. Hasegawa, S. Tamaki, H. Yajima, B. Hashimoto and T. Yaita, Selective separation of samarium(III) by synergistic extraction with $\beta$-diketone and methylphenylphenanthroline carboxamide, Talanta, 2011, 85, 1543-1548.

2 S. Radhika, B.N. Kumar, M.L. Kantam and B.R. Reddy, Liquid-liquid extraction and separation possibilities of heavy and light rare-earths from phosphoric acid solutions with acidic organophosphorus reagents, Sep. Purif. Technol., 2010, 75, 295-302.

3 F. Xie, T.A. Zhang, D. Dreisinger and F. Doyle, A critical review on solvent extraction of rare earths from aqueous solutions, Miner. Eng. 2014, 56, 10-28

4 M.M. Tian, N.Z. Song, D.D. Wang, X.J. Quan, Q. Jia, W.P. Liao and L. Lin, Applications of the binary mixture of sec-octylphenoxyacetic acid and 8-hydroxyquinoline to the extraction of rare earth elements, Hydrometallurgy, 2012, 111, 109-113.

5 M.M. Tian, Q. Jia and W.P. Liao, Studies on synergistic solvent extraction of rare earth elements from nitrate medium by mixtures of 8-hydroxyquinoline with Cyanex 301 or Cyanex 302, J. Rare Earths, 2013, 31, 604-608.

6 H. Asano, H. Itabashi and H. Kawamoto, Separation of iron(III) by di(2-ethylhexyl) phosphate/4-methyl-2-pentanone extraction, J. Iron Steel Inst., Japan, 2001, 87, 623-625.

7 R.K. Mishra, P.C. Rout, K. Sarangi and K.C. Nathsarma, A comparative study on extraction of $\mathrm{Fe}(\mathrm{III})$ from chloride leach liquor using TBP, Cyanex 921 and Cyanex 923, Hydrometallurgy, 2010, 104, 298-303.

8 F. Principe and G.P. Demopoulos, Comparative study of iron(III) separation from zinc sulphate-sulphuric acid solutions using organophosphorus extractants, OPAP and D2EHPA: Part II. Stripping, Hydrometallurgy, 2005, 79, 97-109.

9 J. Saji and M.L.P. Reddy, Liquid-liquid extraction separation of
iron(III) from titania wastes using TBP-MIBK mixed solvent system, Hydrometallurgy, 2001, 61, 81-87.

10 D. Pouillon and F.M. Doyle, Solvent extraction of metals with carboxylic acids - theoretical analysis of extraction behavior, Hydrometallurgy, 1988, 19, 269-288.

11 J.S. Preston, Solvent extraction of metals by carboxylic acids, Hydrometallurgy, 1985, 14, 171-188.

12 J.C. Chen, S. Yu, H. Liu, X. Meng and Z. Wu, New mixed solvent systems for the extraction and separation of ferric iron in sulphate solutions, Hydrometallurgy, 1992, 30, 401-416.

13 J. Sun and T.J. O'Keefe, An evaluation of steel scrap as a reducing agent in the galvanic stripping of iron from D2EHPA, J. Miner. Eng., 2002, 15, 177-185.

14 N.R. Das and S. Lahiri, Liquid-liquid extraction of trace level zirconium and hafnium with trioctylamine, J. Radioanal. Nucl. Chem., 1994, 181, 157-164.

15 M.M. Rajmane, B.M. Sargar, S.V. Mahamuni and M.A. Anuse, Solvent extraction separation of zirconium(IV) from succinate media with N-n-octylaniline, J. Serb. Chem. Soc., 2006, 71, 223-234.

16 Z. Zhu, Y. Pranolo and C. Yong Cheng, Separation of uranium and thorium from rare earths for rare earth production - A review, Miner. Eng., 2015, 77, 185-196.

17 N.E. El-Hefny, Y.A. El-Nadi and J.D. Daoud, Equilibrium and mechanism of samarium extraction from chloride medium using sodium salt of CYANEX 272, Sep. Purif. Technol., 2010, 75, 310-315.

18 B. Gupta, A. Malik and A. Deep, Solvent extraction and separation of tervalent lanthanides and yttrium using CYANEX 923, Solvent Extr. Ion Exch., 2003, 21, 239-258.

19 B.R. Reddy, S. Radhika and B.N.P. Kumar, Liquid-liquid extraction studies of trivalent yttrium from phosphoric acid solutions using TOPS 99 as an extractant, Sep. Purif. Technol., 2010, 45, 1426-1432.

20 D.D. Desai and V.M. Shinde, Liquid anion-exchange extraction and separation of yttrium, neodymium and samarium, Anal. Chim. Acta, $1985,167,413-417$.

21 D.K. Singh, H. Singh and J.N. Mathur, Extraction of rare earths and yttrium with high molecular weight carboxylic acids, Hydrometallurgy, 2006, 81, 174-181.

22 J.N. Mathur and G.R. Choppin, Paraffin wax as a diluent for extraction of actinides and lanthanides with TBP, Solvent Extr. Ion Exc., 1998, 16, 459-469.

23 E. Panturu, D.P. Georgescu, F. Aurelian and N. Udrea, Selective separation of yttrium from chemical concentrate of rare earth, Dev. Miner. Process., 2000, 13, C6-84-C6-89.

24 Z. Marczenko and M. Balcerzak, Separation, Preconcentration and Spectrophotometry in Inorganic Analysis, vol. 10, Elsevier, Amsterdam, Netherlands, 2000, pp. 227-477.

25 C.K. Gupta and N. Krishnamurthy, Extractive Metallurgy of Rare Earths, CRC Press, Boca Raton, FL, USA, 2005.

26 E.H. Borai, M.S. Abd El-Ghany,I.M. Ahmed, M.M. Hamed, A.M. Shahr El-Din and H.F. Aly. Modified acidic leaching for selective separation of thorium, phosphate and rare earth concentrates from Egyptian crude monazite Int. J. Miner Process., 2016, 149, 34-41.

27 N.S. Awwad, Y.A. El-Nadi and M.M. Hamed, Successive processes for purification and extraction of phosphoric acid produced by wet process, Chem. Eng. Proces., 2013, 74, 69-74.

28 C. Wang and D. Li, Extraction of Metal Ions, Value Adding through Solvent Extraction, ISEC'96 19-23 March, Melbourne, 1996, 1, pp. 243-248.

29 A. Sadigzadeh, S. Chehrenama and H. Shokri, Solvent extraction of zirconium from nitric-hydrochloric acid solutions using TBP, J. Theor. Appl. Phys., 2009, 3, 20-26.

30 M. Eskandari Nasab, A. Sam and S.A. Milani, Determination of optimum process conditions for the separation of thorium and rare earth elements by solvent extraction, Hydrometallurgy, 2011, 106, 141-147.

31 S.N. Patkar, A.S. Burungale and R.J. Patil, Separation and liquid-liquid extraction of thorium (IV) as sulphate complex with synergistic mixture of N-n-octylaniline and trioctylamine as an extractant, Rasayan J. Chem., 2009, 2, 825-832. 
32 E.H. Borai, A.M. Shahr El-Din, E.A. EL-Sofany, A.A. Sakr and G.O. El-Sayed, Extraction and separation of some naturally occurring radionuclides from rare earth elements by different amines, Arab J. Nucl. Sci. Appl., 2014, 47, 48-60.

33 V.S. Shimidt, Amine Extraction, Translated from Russian by J. Schmorak. Keter Press, Jerusalem, 1971.

34 J.S. Kim, B.N. Kumar, S. Radhika, M. Lakshmi Kantam and B. Ramachandra Reddy, Studies on selection of solvent extractant system for the separation of trivalent $\mathrm{Sm}, \mathrm{Gd}$, Dy and Y from chloride solutions, Int. J. Miner Process, 2012, 112, 37-42.

35 J. C. Amaral and C.A. Morais, Thorium and uranium extraction from rare earth elements in monazite sulfuric acid liquor through solvent extraction, Miner. Eng., 2010, 23, 498-503.

36 F. Zhang, W. Wu, X. Bian and W. Zeng, Synergistic extraction and separation of lanthanum (III) and cerium (III) using a mixture of 2-ethylhexylphosphonicmono-2-ethylhexyl ester and di-2-ethylhexyl phosphoric acid in the presence of two complexing agents containing lactic acid and citric acid, Hydrometallurgy, 2014, 149, 238-243.

37 G.M. Ritcey and A.W. Ashbrook, Solvent Extraction: Principles and Applications to Process Metallurgy, Part I, Elsevier, Amsterdam, 1984.

38 O.A. Desouky, A.M. Daher, Y.K. Abdel-Monem and A.A. Galhoum, Liquid-liquid extraction of yttrium using primene-JMT from acidic sulfate solutions, Hydrometallurgy, 2009, 96, 313-317.

39 I.M. Ahmed, Solvent Extraction Separation Study of Fe(III) from Sulphate Medium by CYANEX 272 in kerosene, Arab J. Nucl. Sci. Appl., 2013, 46, 48-55.

40 T.A. Lasheen, O.M. El-Hussaini, E.M. Helmy, M.A. Hady and A.A. Manaa, Chemical studies on liquid-liquid extraction of titanium (IV) and Iron (III) from titania waste solution using di-(2-ethylhexyl) phosphoric acid solvent, Arab J. Nucl. Sci. Appl., 2012, 45, 1-13.

$41 \mathrm{M}$. Li, Z. He and L. Zhou, Removal of iron from industrial grade aluminum sulfate by primary amine extraction system, Hydrometallurgy, 2011, 106, 170-174. 